\title{
COVID-19 Infection and Haematological Involvement: a Review of Epidemiology, Pathophysiology and Prognosis of Full Blood Count Findings
}

\author{
Odyssefs A. Violetis ${ }^{1}$ (D) Angeliki M. Chasouraki ${ }^{1} \cdot$ Alexandra M. Giannou $^{1} \cdot$ loannis G. Baraboutis ${ }^{1}$
}

Accepted: 23 June 2020 / Published online: 29 June 2020

(C) Springer Nature Switzerland AG 2020

\begin{abstract}
The unfolding COVID-19 pandemic began in December 2019 in Wuhan, Hubei Province. COVID-19 is a systemic infection affecting several systems including the haematopoietic system. Surveys illustrating the laboratory findings of these patients conclude that lymphocytopenia, neutrophilia and thrombocytopenia are prominent amongst them. Moreover, it has been reported a significant decrease in T lymphocyte subsets and an increase of inflammatory cytokines of hospitalized patients with COVID19. Generally, thrombocytopenia is commonplace in critically ill patients and usually suggests serious organ malfunction. In view of this, this review investigates the correlation between these abnormalities and the prognosis and disease course. Full blood count is an easy, economic and widely available tool which may help to discriminate between patients with or without severe disease. Last but not least, this review examines potential pathophysiological mechanisms by the novel coronavirus which contribute to these haematological alterations aiding the clinicians to better understand this disease and provide more clinical treatment options.
\end{abstract}

Keywords COVID-19 · SARS-CoV-2 · White blood cells · Neutrophilia $\cdot$ Lymphocytopenia $\cdot$ Thrombocytopenia $\cdot$ Cytokine release syndrome

\section{Introduction}

Severe acute respiratory syndrome 2 (SARS-CoV-2) was first recognized in Wuhan, China, in December 2019 causing coronavirus disease 2019 (COVID-19) and has swiftly spread all over the world infecting approximately 4 billion individuals

This article is part of the Topical Collection on Covid-19

Odyssefs A. Violetis

odysseas.violetis@gmail.com

Angeliki M. Chasouraki

angchasouraki@gmail.com

Alexandra M. Giannou

alyannou@outlook.com.gr

Ioannis G. Baraboutis

ioannisbaraboutis@yahoo.gr; i-baraboutis@pammakaristos-hosp.gr

1 Internal Medicine Clinic, Pammakaristos Hospital of Divine Providence (Reference Centre for COVID-19 Infection), Iakovaton 43, 11144 Athens, Greece until May 10. The World Health Organization has already issued a proclamation characterizing the COVID-19 outbreak a pandemic (https://www.who.int/emergencies/diseases/novelcoronavirus-2019) [1]. Coronaviruses (CoVs) are a large family of respiratory viruses that can cause diseases ranging from the common cold to severe acute respiratory syndrome (SARS) and Middle East respiratory syndrome (MERS) [2, 3]. SARS-CoV was the cause of the former infection which first appeared in China in 2002 but ultimately was first isolated in Vietnam a few months later by the Italian doctor Carlo Urbani [4]. The outbreak of SARS affected 17 countries and provoked 774 deaths out of 8096 laboratory-confirmed cases (https://www.who.int/ csr/sars/en/). Regarding the latter infection, the responsible virus was the Middle East respiratory syndrome (MERS)$\mathrm{CoV}$ that, in 2012, was first reported in Saudi Arabia [3]. MERS has been found in 27 countries, mostly in the Middle East, and occasionally reappears in human population due to the ongoing contact with dromedary camels. Until November 2019, MERS has caused 858 deaths out of 2494 laboratoryconfirmed cases (https://www.who.int/emergencies/mers-cov/ en/). COVID-19 infection is regarded as a systemic disease due to the fact that aside from the respiratory system, it affects 
several other systems such as cardiovascular [5], neurological [6], haematopoietic [7, 8], gastrointestinal, [9] and immune [10]. Herein, we summarize the hematologic findings on full blood count focusing on white blood cells and platelets analysing their pathophysiology and their potential use as a tool for spotting the patients who are prone to a more severe progression of the disease or even a lethal upshot.

\section{General Inspection of a Full Blood Count}

Guen et al. released a grand survey examining the clinical and laboratory characteristics of 1.099 patients infected with COVID-19. They reported that admission lymphocytopenia, thrombocytopenia and leukopenia were quite prevalent. In detail, $83.2 \%$ of the patients presented with lymphocytopenia, which was defined as a lymphocyte count of less than $1500 \mathrm{~mm}^{3}$ whereas $36.2 \%$ of them presented with thrombocytopenia, which was defined as a platelet count of less than $150,000 \mathrm{~mm}^{3}$. With regard to leukopenia (WBC less than $4000 \mathrm{~mm}^{3}$ ), it was apparent in $33.7 \%$ of the patients.

Furthermore, the incidence of these abnormalities in the blood cell count was in line with the severity of the disease. Hence, the patients, who suffered from a more severe disease, tended to have more pronounced abnormalities in comparison with those with mild disease $(91.1 \%$ vs $80.4 \%$ as concerned to lymphocytopenia, $57.7 \%$ vs $31.6 \%$ as concerned to thrombocytopenia and $61.1 \%$ vs $28.1 \%$ as concerned to leukopenia respectively) [11].

\section{Neutrophil-Eosinophil Findings: Epidemiology, Pathophysiology and Prognosis}

Wang et al. examined the kinetics of the laboratory parameters in 138 patients infected by COVID-19 during their hospitalization. Thirty-three patients came down with severe disease and 5 patients eventually died. Comparing the laboratory data derived from the patients who were admitted in ICU to those who did not, it can be clearly seen that the data differ. With regard to white blood count and neutrophil count, higher levels were observed on the first group, notably 1.5 -fold and 1.7-fold higher respectively. Furthermore, it has been mentioned that the non-survivors were more frequently prone to develop leukocytosis [12]. Similarly, the study published by Huang et al. advocates that leukocytosis (2.0-fold rise) and neutrophilia (4.4-fold rise) were predictors of the severity of the disease, which was confirmed by the need for admission in an ICU environment, while examining 140 patients with COVID-19 infection [13]. According to a meta-analysis, the patients with severe disease presented a slight increase in their white blood cells while those who did not survive presented a significant increase. Thus, it is recommended that WCC should be examined on a regular basis on the grounds that the increase of the white blood cells in a patient with severe disease may indicate clinical deterioration and a grave outcome. The increase of neutrophils accounted for the surge of the white blood cells as the other bloodlines (lymphocytes, monocytes and eosinophils) dropped [14]. The available literature advocates that neutrophilia is an expression of the cytokine storm and hyperinflammatory state which have an important pathogenetic role in COVID-19 and related infections such as SARS $[10,13,15,16]$. Neutrophilia may also indicate a superimposed bacterial infection [17].

Another potential application of data derived from the FBC would be to use formulas such as neutrophil-to-lymphocyte ratio (NLR), platelet-to-lymphocyte ratio and monocyte-tolymphocyte ratio to act as surrogates to assess the extent of systemic inflammation. Although an extensive study is at this point lacking, Qin et al. have reported an increase in NLR in patients with severe disease compared with those without [17].

To date, regarding eosinophil count, literature suggests that there is no link between low eosinophils and the severity of the disease [18].

\section{Lymphocytopenia: Epidemiology, Pathophysiology and Prognosis}

Several factors might play an important role in the pathophysiology of lymphocytopenia. Firstly, it has been discovered that angiotensin-converting enzyme 2 receptors (ACE2 receptors) are likely the cell receptor of COVID-19, which was also the receptor for SARS-CoV [19]. Therefore, cells which express ACE2 receptors are susceptible to COVID-19 infection. Nonetheless, there had been no evidence that lymphocytes could express those receptors which could make them vulnerable to the new virus. However, a study published by Xu et al. demonstrated that ACE2 receptors were expressed in lymphocytes in oral mucosa, lungs and digestive system [20]. Hence, the direct impact of the virus on the lymphocytes, which could induce their lysis, does not seem unfounded. Moreover, COVID-19 infection causes the production of inflammatory cytokines such as IL-6, IL-2, IL-7, granulocyte-colony stimulating factor, interferon- $\gamma$-inducible protein 10 , MCP-1, MIP1-a and TNF-a, recognizable as a cytokine storm, which leads to not only lymphocytes' apoptosis but also lymphoid organs' atrophy (e.g. the spleen) [21].

As already mentioned above, lymphocytopenia is a strong predictor of the severity of the disease. In China, patients who ultimately required ICU environment during their hospitalization presented a more significant drop in lymphocyte count compared with those who did not $[12,13]$. These findings are consistent with studies in Singapore [22]. Moreover, lymphocytopenia was highly correlated with the severity of lung injury [23]. 
Lymphocytopenia was also associated with survival incidence, as non-survivors presented a more considerable decrease in lymphocyte count compared with survivors [12]. In a US study from Washington DC, lymphocytopenia was prominent amongst critically ill patients [24].

A retrospective study by $\mathrm{BO} X \mathrm{XU}$ et al. examined the alteration of lymphocyte subsets in patients with COVID-19. The findings illustrate that the patients who were categorized as severely ill and critically ill including those who passed away experienced a considerable dip of $\mathrm{T}$ lymphocyte subset counts. Particularly, in critically ill and severely ill patients, the median counts of lymphocyte, CD3+ T cell, CD4+ T cell and CD8+ $\mathrm{T}$ cell were declined to almost a third and about two-thirds of median counts values respectively when they were compared with mildly ill patients. In patients who died during their hospital stay, the median lymphocyte, CD3+ T cell, CD4+ T cell, CD8+ T cell, B cell and NK-cell were observed to be lower than other critically ill patients [25]. Another study concluded that there was no difference in $\mathrm{CD}^{+} / \mathrm{CD}^{+}$ratio between healthy controls and patients with COVID-19 or between those with mild disease and those with severe disease [26].

\section{Thrombocytopenia: Epidemiology, Pathophysiology and Prognosis}

Thrombocytopenia is a well-known predictor of mortality in the ICU environment and it is used in several disease severity scores. A meta-analysis conducted by Lippi G. et al. included 9 studies with a total of 1779 COVID-19 patients examining the association between thrombocytopenia and severity of the disease. It was revealed that low platelet count was associated with a threefold enhanced risk of severe disease and with a fatal outcome. Taking a closer look, the analysis showed that platelet count was significantly lower in patients with more severe COVID-19 (WMD $-31 \times 109 / \mathrm{L} ; 95 \% \mathrm{CI}$, from -35 to $-29 \times 109 / \mathrm{L}$ ) while the subgroup analysis of three studies, whose primary outcome was mortality, showed a more significant drop in platelets in non-survivors (WMD, $-48 \times 109 / \mathrm{L}$; $95 \% \mathrm{CI},-57$ to $-39 \times 109 / \mathrm{L} ; \mathrm{I} 2,91 \% ; p<0.001)$ [27].

Several hypotheses regarding the pathophysiological mechanisms, which could lead to low platelet count in patients infected with COVID-19, have been cited. To begin with, it is speculated that COVID-19 has similar action with a frequent common cold's coronavirus, HCoV-229E. This speculation derived from the genome similarities between COVID-19 and SARS virus and SARS virus and $\mathrm{HCoV}-229 \mathrm{E}$ respectively. $\mathrm{HCoV}-229 \mathrm{E}$ binds CD13 receptors which are expressed on the surface of haematopoietic and stromal cells in the bone marrow leading to their apoptosis and consequently to haematopoiesis inhibition. In addition, the induced cytokine storm after the COVID19 infection, which has similarities with secondary haemophagocytic lymphohistiocytosis (sHLH), may play a role in thrombocytopenia through destruction of the haematopoietic progenitor cells. In parallel with HIV infection, COVID-19 may produce autoantibodies and complexes specific to platelets' antigens resulting in their destruction by the reticuloendothelial system [28]. A large number of existing studies in the broader literature have examined the platelets biogenesis in the lung circulation. Experiments in mice suggest that megakaryocytes and large cytoplasmic fragments are produced in the bone marrow, then they emigrate to the pulmonary circulation and eventually are transformed into platelets under the shear stress and the turbulence into pulmonary vasculature. Those findings can only indirectly be confirmed in humans [29]. Therefore, it is speculated that lung injury caused by COVID-19 infection may limit sites with preserved endothelium that could participate in platelet production from intravascular megakaryocytes [28]. Most patients with COVID-19 who have thrombocytopenia have elevated D-dimer levels and impaired coagulation time and the majority of the patients with lethal outcome fulfil the clinical criteria for disseminated intravascular coagulation (DIC) [30]. Patients presenting with a virus infection may develop sepsis which is well established as a common cause of DIC. The development of DIC results when leukocytes, platelets and endothelial cells are activated to inducing dysregulation of thrombin formation that occurs both systemically and locally in the lungs of the patients with severe pneumonia. Circulation of free thrombin, uncontrolled by natural anticoagulants, can activate platelets and stimulate fibrinolysis [31]. For that reason, it is conjectured that platelet consumption during microthrombus formation in DIC is one of the pathogenic mechanisms explaining the profound thrombocytopenia.

\section{Conclusion}

In summary, findings on full blood count could indicate the patients who suffer from severe disease and could be used as a prognostic tool by the clinicians. Leukocytosis, neutrophilia, lymphocytopenia and thrombocytopenia are prominent in patients with severe disease. These markers may play a role not only in a more efficient triage of those patients on admission but also during their hospitalization so that more vigorous therapeutic procedures should follow. Even though corticosteroids are known to cause lymphocytopenia, recently published experience suggests that the lymphocyte count promptly recovers after an initial drop with the use of corticosteroids (namely dexamethasone) in severe COVID-19 infection [32]. Dexamethasone seems to benefit patients with severe COVID-19 infection, according to a recent announcement by the RECOVERY investigators (https://www.recoverytrial.net/ news/low-cost-dexamethasone-reduces-death-by-up-to-onethird-in-hospitalised-patients-with-severe-respiratorycomplications-of-covid-19). 
Moreover, flow cytometry is likely to be used for the same purposes and for investigating how the immune system responds to the infection by the new virus. Finally, the pathophysiological mechanisms which lead to these abnormalities should be investigated thoroughly by the forthcoming studies as until now there is a lack of knowledge. The collected data were mostly based on Asian population since data from other nationalities are not yet available. Therefore, with the release of new publications, this information may need to be further evaluated.

Author Contributions OV: conceptualized the subject of the review, scrutinized the literature, wrote the review, critically reviewed and revised the manuscript and gave final approval of the version to be published. IB: supervised the authors' work. AC, AG: contributed to the development of the review through productive brainstorming

\section{Compliance with Ethical Standards}

Conflict of Interest The authors declare that they have no conflict of interest.

This article does not contain any studies with human or animal subjects performed by the authors.

The authors consent to submit this article.

\section{References}

1. Zhu N, Zhang D, Wang W, et al. A novel coronavirus from patients with pneumonia in China, 2019. N Engl J Med. 2020;382(8):72733. https://doi.org/10.1056/NEJMoa2001017.

2. Drosten C, Günther S, Preiser W, van der Werf S, Brodt HR, Becker $\mathrm{S}$, et al. Identification of a novel coronavirus in patients with severe acute respiratory syndrome. N Engl J Med. 2003;348(20):1967-76.

3. Zaki AM, van Boheemen S, Bestebroer TM, Osterhaus AD, Fouchier RA. Isolation of a novel coronavirus from a man with pneumonia in Saudi Arabia. N Engl J Med. 2012;367(19):1814 20. https://doi.org/10.1056/NEJMoa1211721.

4. Kuiken T, Fouchier RA, Schutten M, Rimmelzwaan GF, van Amerongen G, van Riel D, et al. Newly discovered coronavirus as the primary cause of severe acute respiratory syndrome. Lancet. 2003;362(9380):263-70.

5. Bansal M. Cardiovascular disease and COVID-19. Diabetes Metab Syndr. 2020;14(3):247-50, Published online 2020 Mar 25. https:// doi.org/10.1016/j.dsx.2020.03.013.

6. Mao L, Jin H, Wang H, et al. Neurologic manifestations of hospitalized patients with coronavirus disease 2019 in Wuhan, China. JAMA Neurol. 2020;77:683. https://doi.org/10.1001/jamaneurol. 2020.1127.

7. Connors JM, Levy JH. COVID-19 and its implications for thrombosis and anticoagulation. Blood. 2020;135:2033-40. https://doi. org/10.1182/blood.2020006000.

8. Bikdeli B, Madhavan MV, Jimeniez D, et al. COVID-19 and thrombotic or thromboembolic disease : implications for prevention, antithrombotic therapy and follow-up. J Am Coll Cardiol. 2020;75:2950-73. https://doi.org/10.1016/j.jacc.2020.04.031.

9. Wong SH, Lui RN, Sung JJ. Covid-19 and the digestive system. J Gastroenterol Hepatol. 2020;35(5):744-8. https://doi.org/10.1111/ jgh.15047.

10. Mehta P, McAuley DF, Brown M, Sanchez E, Tattersall RS, Manson JJ, et al. COVID-19: consider cytokine storm and immunosuppression. LANCET. 2020;395(10229):1033-4. https:// doi.org/10.1016/S0140-6736(20)30628-0.

11. Guan WJ, Ni ZY, Hu Y, Liang WH, Ou CQ, He JX, et al. Clinical characteristics of coronavirus disease 2019 in China. N Engl J Med. 2020;382:1708-20. https://doi.org/10.1056/NEJMoa2002032.

12. Wang $\mathrm{D}, \mathrm{Hu} \mathrm{B}, \mathrm{Hu} \mathrm{C}, \mathrm{Zhu} \mathrm{F}$, Liu X, Zhang J, et al. Clinical characteristics of 138 hospitalized patients with 2019 novel coronavirus-infected pneumonia in Wuhan, China. JAMA. 2020;323:1061. https://doi.org/10.1001/jama.2020.1585.

13. Huang $\mathrm{C}$, Wang Y, Li X, Ren L, Zhao J, Hu Y, et al. Clinical features of patients infected with 2019 novel coronavirus in Wuhan, China. Lancet. 2020;395(10223):497-506. https://doi. org/10.1016/S0140-6736(20)30183-5.

14. Henry BM, de Oliveira MHS, Benoit S, Plebani M, Lippi G. Hematologic, biochemical and immune biomarker abnormalities associated with severe illness and mortality in coronavirus disease 2019 (COVID-19): a meta-analysis. Clin Chem Lab Med. 2020;58: 1021-8. https://doi.org/10.1515/cclm-2020-0369.

15. Giamarellos-Bourboulis EJ, Netea MG, Rovina N, et al. Complex immune dysregulation in COVID-19 patients with severe respiratory failure. Clinical and Translational Report. Online Now. Cell Host and Microbe. 2020 Open Access. https://doi.org/10.1016/j. chom.2020.04.009.

16. Qin C, Zhou L, Hu Z, Zhang S, Yang S, Tao Y, et al. Dysregulation of immune response in patients with COVID-19 in Wuhan, China. Clin Infect Dis. 2020. https://doi.org/10.1093/cid/ciaa248.

17. Lippi G, Plebani M. The critical role of laboratory medicine during coronavirus disease 2019 (COVID- 19) and other viral outbreaks. Clin Chem Lab Med. 2020;58:1063-9. https://doi.org/10.1515/ cclm-2020-0240.

18. Lippi G, Henry BM. Eosinophil count in severe coronavirus disease 2019. QJM Int J Med. 2020. https://doi.org/10.1093/qjmed/ hcaa137.

19. Xu X, Chen P, Wang J, Feng J, Zhou H, Li X, et al. Evolution of the novel coronavirus from the ongoing Wuhan outbreak and modeling of its spike protein for risk of human transmission. Sci China Life Sci. 2020;63(3):457-60. https://doi.org/10.1007/s11427-020-1637-5.

20. Xu H, Zhong L, Deng J, Peng J, Dan H, Zeng X, et al. High expression of ACE2 receptor of 2019-nCoV on the epithelial cells of oral mucosa. Int J Oral Sci. 2020;12:8. https://doi.org/10.1038/ s41368-020-0074-x.

21. Terpos E, Ntanasis-Stathopoulos I, Elalamy I, Kastritis E, Sergentanis TN, Politou M, et al. Hematological findings and complications of COVID-19. Am J Hematol. 2020;95:834-47. https:// doi.org/10.1002/ajh.25829.

22. Fan BE, Chong VCL, Chan SSW, Lim GH, Lim KGE, Tan GB, et al. Hematologic parameters in patients with COVID-19 infection. Am J Hematol. 2020;95:E131-4. https://doi.org/10.1002/ajh. 25774.

23. Liu Y, Yang Y, Zhang C, Huang F, Wang F, Yuan J, et al. Clinical and biochemical indexes from $2019-\mathrm{nCoV}$ infected patients linked to viral loads and lung injury. Sci China Life Sci. 2020;63(3):364 74. https://doi.org/10.1007/s11427-020-1643-8.

24. Arentz M, Yim E, Klaff L, Lokhandwala S, Riedo FX, Chong M, et al. Characteristics and outcomes of 21 critically ill patients with COVID-19 in Washington state. JAMA. 2020;323(16):1612-4. https://doi.org/10.1001/jama.2020.4326.

25. Xu B, Fan CY, Wang AL, Zou YL, Yu YH, He C, et al. Suppressed $\mathrm{T}$ cell-mediated immunity in patients with COVID-19: a clinical retrospective study in Wuhan, China. J Inf Secur. 2020;81:e5160. https://doi.org/10.1016/j.jinf.2020.04.012.

26. Wang F, Nie J, Wang H, Zhao Q, Xiong Y, Deng L, et al. Characteristics of peripheral lymphocyte subset alteration in COVID-19 pneumonia. J Infect Dis. 2020;221:1762-9. https:// doi.org/10.1093/infdis/jiaa150. 
27. Lippi G, Plebani M, Henry BM. Thrombocytopenia is associated with severe coronavirus disease 2019 (COVID-19) infections: a meta-analysis. Clin Chim Acta. 2020;506:145-8. https://doi.org/ 10.1016/j.cca.2020.03.022.

28. Xu P, Zhou Q, Xu J. Mechanism of thrombocytopenia in COVID19 patients. Ann Hematol. 2020;15:1-4. https://doi.org/10.1007/ s00277-020-04019-0.

29. Lefrançais E, Looney MR. Platelet biogenesis in the lung circulation. Physiology. 2019;34(6):392-401. https://doi.org/10.1152/ physiol.00017.2019.

30. Tang N, Li D, Wang X, Sun Z. Abnormal coagulation parameters are associated with poor prognosis in patients with novel coronavirus pneumonia. J Thromb Haemost. 2020;18:844-7. https://doi.org/10.1111/jth.14768.

31. Lillicrap D. Disseminated intravascular coagulation in patients with 2019-nCoV pneumonia. J Thromb Haemost. 2020;18(4):786-7. https://doi.org/10.1111/jth.14781.

32. Baraboutis IG, Gargalianos P, Aggelonidou E, et al. Initial real-life experience from a designated COVID-19 centre in Athens, Greece: a proposed therapeutic algorithm. SN Compr Clin Med. 2020;2: 689-93. https://doi.org/10.1007/s42399-020-00324-x.

Publisher's Note Springer Nature remains neutral with regard to jurisdictional claims in published maps and institutional affiliations. 